\title{
Poster Sessions
}

Particle morphology of energetic materials to a great extent defines their sensitivity and reactivity properties. The morphology in its turn strongly depends on the crystallization process. In the present research the thermal crystallization of pentaerythrol tetranitrate (PETN) explosive and ammonium perchlorate (AP) was studied by differential scanning calorimetry (DSC) and FT-IR spectroscopy. DSC test usually included the heating of the sample with the constant rate of $5{ }^{\circ} \mathrm{C} / \mathrm{min}$ to the temperature which was several degrees higher than the melting temperature and then the cooling of the sample with the different cooling rates. The cooling led to the crystallization. The crystallization temperature, heat and rate were measured. The newly crystallized samples were then subjected to microscopic inspection and FT-IR spectroscopy.

It was found that the crystallization of AP takes place in two stages. The first high temperature stage proceeds at temperatures higher than the melting temperature and starts just after beginning of cooling. The second low temperature stage occurs at temperature significantly less than the melting temperature, e.g. the crystallization is realized from the overcooled liquid. The relative contributions of these types of crystallization strongly depend on the cooling rate. At low cooling rate $\left(0.2^{\circ} \mathrm{C} / \mathrm{min}\right)$ the crystallization takes place through the high temperature mechanism solely whereas at high cooling rate $\left(15^{\circ} \mathrm{C} / \mathrm{min}\right)$ only low temperature process is realized. At intermediate cooling rates both types of crystallization exist. The ratio of the heat of low temperature crystallization to the high temperature one $\left(\mathrm{H}_{\text {lowtemp }} / \mathrm{H}_{\text {hightemp }}\right)$ increases exponentially with the cooling rate. FT-IR spectroscopy showed that the AP sample crystallized through the high temperature mechanism has strictly the same spectrum as the initial material. The spectrum of AP crystallized from the overcooled melt demonstrates certain differences (line shapes and frequencies) in the range of $\mathrm{NH}_{4}{ }^{+}$stretching $\left(\approx 3200 \mathrm{~cm}^{-1}\right)$ and bending $\left(\approx 1400 \mathrm{~cm}^{-1}\right)$ vibrations and $\mathrm{ClO}_{4}^{-}$stretching $\left(\approx 1100 \mathrm{~cm}^{-1}\right)$ vibrations. These facts testify perhaps that the different mechanisms of crystallization result in formation of different crystal structures.

Crystallization of PETN in all experiments takes place from the overcooled melt and proceeds in one stage. The value of the overcooling depends on the cooling rate. At low cooling rates (up to $4^{\circ} \mathrm{C} / \mathrm{min}$ ) the crystallization temperature is approximately constant and concentrates near $120^{\circ} \mathrm{C}\left(\mathrm{T}_{\text {melt }}=141{ }^{\circ} \mathrm{C}\right)$. The further rise of the cooling rate (from $5^{\circ} \mathrm{C} / \mathrm{min}$ and up to $15^{\circ} \mathrm{C} / \mathrm{min}$ ) results in the sharp increase of the overcooling $\left(\mathrm{T}_{\text {cryst }} \approx 100^{\circ} \mathrm{C}\right)$. It was found that the rate of crystallization has the same step like dependence upon the cooling rate. The high overcooling leads to the significant increase of the crystallization rate. FT-IR spectra do not show any differences between initial and newly crystallized samples. However visual and microscopic inspection show that in the case of low rate crystallization (low overcooling) the newly formed crystals have a regular needle like shape, while the high rate crystallization (high overcooling) results in formation of irregular mainly small-sized particles.

Keywords: crystallization, energetic, DTA

\section{MS35.P24}

Acta Cryst. (2011) A67, C464

Growth decorations on facets of Al-Cu-Fe single quasicrystals

Marian Surowiec, ${ }^{\mathrm{a}}$ Włodzimierz Bogdanowicz, ${ }^{\mathrm{a}}$ Paweł Zamrzycki, ${ }^{a}$ Bolesław Formanek, ${ }^{\mathrm{b}}$ Maria Sozańska, ${ }^{\mathrm{b}}$ Insitute of Material Science, Univ. of Silesia, 40 007Katowice, ${ }^{b}$ Faculty of Materials Engineering and Metallurgy, Silesian Univ. of Technology, 40-019 Katowice (Poland). E-mail: msurowie@us.edu.pl

The contribution reports on investigations of facet decorations formed during crystallization of polygonal single quasicrystalline $\psi$ phase occurring in $\mathrm{Al}-\mathrm{Cu}-\mathrm{Fe}$ alloy. The perfectly stable icosahedral single quasicrystals of $\psi$ phase are formed in the range of compositional triangle $\mathrm{Al}_{62.4} \mathrm{Cu}_{24.4} \mathrm{Fe}_{13.2}, \mathrm{Al}_{65} \mathrm{Cu}_{23} \mathrm{Fe}_{12}$ and $\mathrm{Al}_{61} \mathrm{Cu}_{28.4} \mathrm{Fe}_{10.6}$ [1-4].

Polyhedral equilibrium single grains of the $\psi$ phase were obtained inside of ingots of an $\mathrm{Al}-\mathrm{Cu}-\mathrm{Fe}$ alloy, for which the nominal composition was 65 at. $\% \mathrm{Al}, 20$ at. $\% \mathrm{Cu}$ and 15 at.\% Fe. The specimens were synthesized in a helium atmosphere using the Bridgman-CzochralskiGrowth (BCG) apparatus equipped with an induction furnace. The growth morphology was investigated by the scanning electron microscopy (SEM) using primary and secondary electrons. The selected area diffraction (SAD) as well as X-ray powder diffraction were applied [5].

Single quasicrystals of $\psi$ phase $\mathrm{Al}_{6} \mathrm{Cu}_{2} \mathrm{Fe}$ exhibit icosahedral symmetry with pentagonal dodecahedral growth forms - 12 faces perpendicular to the 5-fold axes (Fig. 1 (a)). The dodecahedra have irregularities and different dimensions of edges extending up to 160 $\mu \mathrm{m}$. The faces of dodecahedra are not perfectly smooth and show residual flux. Some of the dodecahedra are uniformly covered by primary cellular decorations gradually covering almost all facets. During the next stage of crystallization, the secondary fractal like decorations appeared on the quasicrystals surfaces (Fig. 1(b)). There was no evident difference in chemical composition between the inner dodecahedra, primary cellular decorations as well as the secondary fractal like decorations.

The facets of dodecahedra are decorated in similar way as fivefold facets of quasicrystals units of Al-Pd-Mn found by Beeli and Nissen [6]. Contrary to their conclusion we don't found a relationship between facet symmetry and the symmetry of dendrites. The decorations can be formed during the last stage of crystallization, when residual flux crystallizes on the quasicrystal facet in a form of solid dendrites.

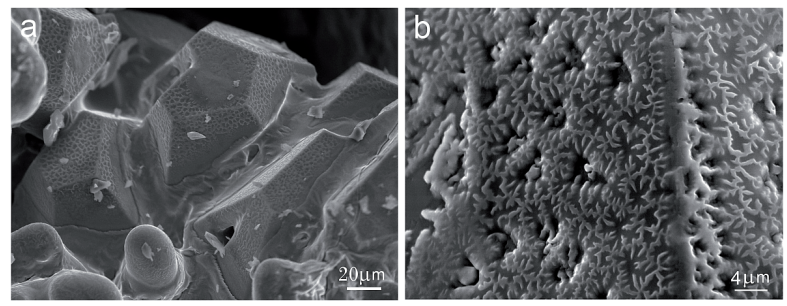

Fig. 1. Decorations on pentagonal faces of the $\psi$ phase. Primary cellular decoration (a) and secondary fractal like decoration (b).

[1] F.W. Gayle, A.J. Shapiro, F.S. Biancanello, W.J. Böttinger, Metall. Trans. 1992, A23, 2409-2417. [2] A.P. Prevarskyi, Russ. Met. 1971, 4, 154-156. [3] D. Gratias, Y. Calvayrac, J. Devaud-Rzepski, F. Faudot, M. Harmelin, A. Quivy P.A. Bancel, J. Non-Cryst. Solids, 1993, 482, 153-154. [4] C.P. Wang, X.J. Liu, L. Zhang, K. Ishida, Landolt - Börnstein New Series, IV/11 A2, Springer 2005, 1-37.[5] M. Surowiec, W. Bogdanowicz, J. Krawczyk, B. Formanek and M. Sozanska, Phil. Mag. DOI:10.1080/14786435.2010.528460. [6] C. Beeli and H.-U. Nissen, Phil. Mag. B, 1993, 68, 487-512.

Keywords: Al-Cu-Fe system, quasicrystal growth morphology, decoration of facets.

\section{MS35.P25}

Acta Cryst. (2011) A67, C464-C465

Uncoupling nucleation and protein crystal growth using microfluidic chips

Pascal Rigolet, ${ }^{d}$ Malika Lounaci, ${ }^{a}$ Yong Chen, ${ }^{\text {bc }}{ }^{a}$ Laboratoire Sciences Analytiques, Bioanalytiques et Miniaturisation, ESPCI, 10 Rue Vauquelin, 75231 PARIS, (France). ${ }^{b}$ Ecole Normale Supérieure of Paris, CNRS-ENS-UPMC UMR 8640, 24 rue Lhomond, 75231 Paris, (France). 'Institute for Integrated Cell-Material Sciences, Kyoto University, Yoshida-Ushinomiya-cho, Sakyo-ku, 606-8507 Kyoto 